OPEN ACCESS

Edited by:

Anik Bhaduri,

Griffith University, Australia

Reviewed by:

Richard Meissner,

Council for Scientific and Industrial

Research (CSIR), South Africa

Animesh Kumar Gain,

University of Kiel, Germany

*Correspondence:

Richard G. Lawford

rlawford@gmail.com;

richard.laword@morgan.edu

Specialty section: This article was submitted to

Freshwater Science,

a section of the journa

Frontiers in Environmental Science

Received: 01 October 2018 Accepted: 10 April 2019

Published: 07 May 2019

Citation:

Lawford RG (2019) A Design for a Data and Information Service to Address the Knowledge Needs of the Water-Energy-Food (W-E-F) Nexus and Strategies to Facilitate Its Implementation.

Front. Environ. Sci. 7:56. doi: 10.3389/fenvs.2019.00056

\section{A Design for a Data and Information Service to Address the Knowledge Needs of the Water-Energy-Food (W-E-F) Nexus and Strategies to Facilitate Its Implementation}

\author{
Richard G. Lawford* \\ Department of Computer, Mathematical and Natural Sciences, GESTAR, Morgan State University, Baltimore, MD, \\ United States
}

Food security is essential to sustain human societies. Food production flourishes when water, energy, and land are abundant, but more often it is limited by scarcities in one or more of these resources. In particular, food production is limited by the relatively fixed amount of water that circulates in the hydrosphere, the lack of new land for crops in many countries, and the depletion of critical minerals and fossil fuels in many source regions. An integrated Water-Energy-Food (W-E-F) Nexus planning and management approach promises improved resource efficiencies, new business opportunities, more coherent resource and environmental policies, and economies of scale for the data and information services underpinning better decision-making. This paper distills discussions on data and information from four regional workshops held as part of a Future Earth W-E-F Nexus Cluster project. The workshops reviewed ways to enhance the sustainability of the W-E-F Nexus through better governance; collecting, analyzing, and communicating data and information; and integrating both with management for better planning and decision-making. The focus of this paper is to explore the potential application of an integrated data and information system to enhance water, energy, and food sustainability. In particular, this paper's objective is to explore how a multisector W-E-F Nexus data and information system could be developed and operated to meet the planning and decision-making information needs of practitioners and to facilitate the implementation of the W-E-F Nexus concept. This "Hypothesis and Theory" paper provides a hypothesis and system design and proposes steps that could be taken to implement and test the system in a W-E-F Nexus environment. Data and information, along with modern technologies, can play a central role in facilitating paradigm shifts that reinforce the W-E-F Nexus by explicitly assessing environmental services, meeting the growing urban food demand, valuing water and other resources used to produce food and energy for export, promoting resource use efficiency through integrated planning and management, and strengthening links between the W-E-F Nexus and appropriate Sustainable Development Goals.

Keywords: W-E-F Nexus, data and information system, satellite observations, decision-making, in situ observations 


\section{BACKGROUND}

Providing adequate food for the world's growing population is a major challenge. Developing the necessary food production capabilities will require more effective and sustainable use of key input resources, most notably water and energy. Securing sustainability in the water, energy, and food sectors is critical for safeguarding terrestrial, freshwater, and marine natural assets; sustaining critical ecosystem services; building healthy, resilient, and productive cities and more prosperous rural futures; and reducing human health risks. As computer power, satellites, and communications technologies improve, they expand the potential to effectively inform decision-makers with requisite resource management information and outlooks.

The W-E-F Nexus refers to the interactions among the water, energy, and food sectors (Figure 1). According to the Food and Agriculture Organization (FAO) of the United Nations (UN), the agri-food sector is responsible for $70 \%$ of global water withdrawals and uses about $30 \%$ of the world's total energy production (Food and Agriculture Organization, 2017). Land is also an important resource: globally, 4.9 billion hectares of land are used for agriculture, of which 33\% are moderately to highly degraded (Food and Agriculture Organization, 2017). Food production capabilities and water and energy availability vary across the globe, which has led to food becoming an extensively traded commodity. The global water cycle, which distributes precipitation and runoff in highly variable regional patterns, cycles a relatively fixed amount of water through the hydrosphere. Both energy and water availability vary from country to country but water is generally treated as a public good, while oil and gas reserves are treated as valuable commodities. Renewable energy, which meets a growing proportion of the world's energy needs, has decentralized supply patterns and its emergence is affecting the energy industry in terms of the demand for oil and, consequently, its price.

The water, energy, and food sectors tend to be managed as three independent ministries in most national governments, which Tett (2015) describes as siloes. It is reasonable to expect

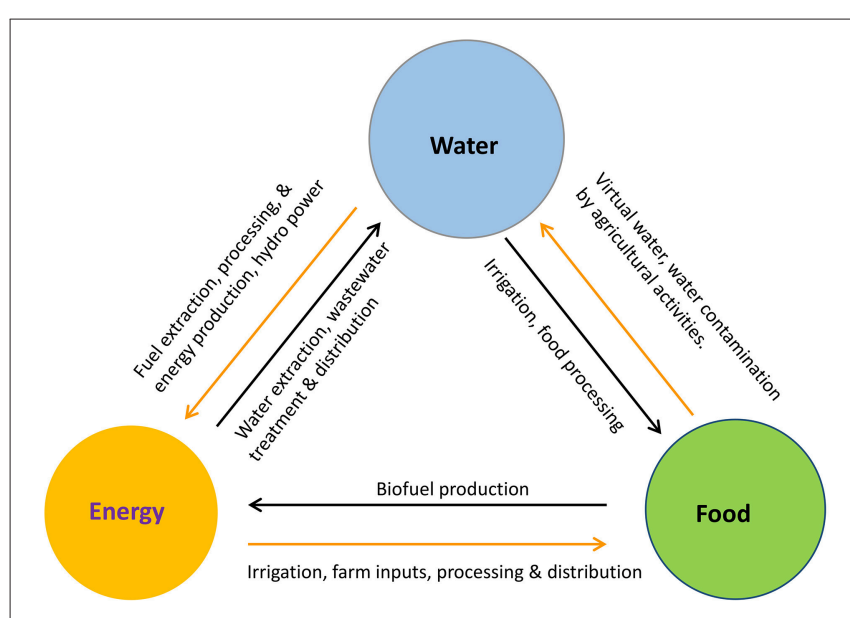

FIGURE 1 | Interactions among the sectors that make up the W-E-F Nexus. that their joint management would provide new efficiencies and lead to synergistic policy developments in areas of ecosystem services and sustainable development. Joint governance could be supported by an information service that provided data products for all aspects of the W-E-F Nexus. Integrated governance and management frameworks, such as the W-E-F Nexus, that rely on open access to data and information in support of advisory services and joint planning would be advanced by the development of joint information services.

A growing number of articles have discussed various aspects of the W-E-F Nexus framework over the last 5 years (Liu et al., 2017). Along with the World Economic Forum's Global Risks 2014 report (World Economic Forum, 2014), these articles introduce the benefits of managing interactions in a more coordinated way. The W-E-F Nexus introduces an integrated approach for systematically analyzing and planning synergies by giving more attention to these interdependencies.

This paper, which fits the Frontiers "Hypothesis and Theory" category best, explores the hypothesis that a suitably defined data and information system that integrates and consolidates W-E-F Nexus data could support the implementation of a Nexus approach. In particular, its objective is to explore how existing selected sector-specific data and tools can be incorporated into a multi-sectoral information system that would meet W-E-F Nexus needs and support its broader implementation. This paper includes: a description of the data and information needed to support planning, management, and trade-offs in the W-E-F Nexus (The W-E-F Nexus Approach, its Benefits, and Its Information Needs); a brief review of W-E-F Nexus data sources and collection systems such as satellite and in situ observational networks (Data Inputs); the supplementary role of models and data assimilation systems (Models and Data Assimilation); an overview of the design and development of an information system that would build on existing systems (Implementing the W-E-F Nexus Data and Information System [WEFDIS]); and conclusions based on the main points addressed in the paper (Developing and Implementing a WEFDIS Network).

\section{THE W-E-F NEXUS APPROACH, ITS BENEFITS, AND ITS INFORMATION NEEDS}

The W-E-F Nexus is a multidisciplinary framework designed to ensure that interactions, synergies, and trade-offs are properly understood and decision-makers have access to the information and tools they need to take full advantage of these potential co-benefits. Globalization, urbanization, industrialization, and climate and environmental change continue to put pressure on water, food, and energy security. The W-E-F Nexus community needs to understand the influences of many factors: trade policies that either promote free trade or protectionism and tariffs, changing prices for oil and gas depending on the politically determined rate of supply, changing affluence and dietary requirements, increasing climate variability and extreme climate events, and the trade-offs needed to balance long- and shortterm needs. 
This paper derives many of its insights from four regional Future Earth W-E-F Nexus Cluster project workshops held between June 2016 and November 2017. Each of the workshops included sessions on in situ and satellite data sources and applications for decision-making and planning. Their findings have been documented and are available at http://water-future. org/past-events-2/ or from the author. The workshops were held in: North America (Washington, D.C.), Europe (Karlsruhe, Germany), Eastern Asia (Kyoto, Japan), and Southern Africa (Hilton, South Africa) and each drew on the expertise available in these regions.

Based on the four workshops, the data and information needs for W-E-F Nexus decision-makers were clarified. Planners need credible predictions and scenarios for developing W-E-F Nexus plans and identifying hotspots where W-E-F Nexus problems are emerging. Operational decision-makers need information to provide guidance on maximizing the benefits of resource use and minimizing the impacts of Nexus operations on environmental quality and biodiversity. Evaluators require information for assessing the viability of biofuels and other renewables to meet energy demands within the W-E-F Nexus and for conducting management reviews. Economic advisors need data for providing recommendations on beneficial trade-offs and for confirming plans to advance W-E-F Nexus productivity.

Critical interactions within the W-E-F Nexus and the availability of observations for monitoring critical processes need to be identified. Consistent observations need to be based on a common understanding of how variables are defined in each sector. A precise and widely accepted lexicon and associated ontologies would facilitate the quantification of interactions among the sectors. Engineered systems can be accurately defined but social, economic, and ecosystem interactions will include uncertainties, so identifying and defining the most critical terms becomes very important. In addition, the W-E-F Nexus itself will need to be defined so that it can encompass environmental effects and anthropogenic change. In addition to trends in land use (Ringler et al., 2013), the Nexus is influenced by growing populations, increasing wealth, changing food preferences, the effects of climate change on water and temperatures, unplanned urbanization, and technological change.

Test beds and use cases could be undertaken to help clarify definitions for terms in a W-E-F Nexus lexicon. A pilot project that explores stresses on the W-E-F Nexus using preliminary integrated definitions and appropriate geospatial data would be useful. It could include an analytical framework that would serve as a test bed for identifying and addressing data gaps more generally (Vörösmarty, 2017).

\section{Information Gaps}

A comprehensive analysis of current data gaps should be undertaken. In some cases, data are missing entirely; in others, only short-duration research data sets exist (see Table 1 for a partial listing). Some data gaps exist because science has not yet fully addressed certain W-E-F Nexus issues or governments have not found the issues important enough to introduce observational networks.
TABLE 1 | Examples of missing observations needed for analysis of the W-E-F Nexus.

\section{Missing observations for W-E-F Nexus Analysis}

Water use in thermoelectric power generating stations and mines

Actual irrigation water use

Runoff and infiltration from land with tile drainage

Soil carbon data

Volume of recycled water

Volume of water used in hydraulic fracking

Volume of food waste

Near real-time water use

Innovative approaches to monitoring are needed to provide information on the sources and volumes of water used for all W-E-F Nexus activities and possible impacts of these activities on the environment. Global water use estimates in agriculture and forestry are needed for improved management and to assess the feasibility of W-E-F Nexus trade-offs. A systematic data and information service based on available techniques needs to be developed.

Links between the W-E-F Nexus and the environment must be better understood and monitored. Water quality data are important for monitoring the relevance of and pathways for food and energy by-products. Nitrogen and phosphorus from crop fertilizers that find their way into waterways and lakes cause eutrophication. The safety and other possible effects of recycled wastewater on crops irrigated with reclaimed water need to be assessed.

Food waste is an emerging W-E-F Nexus issue that also needs to be monitored. SDG Target 12.3 calls for nations to, "By 2030, halve per capita global food waste at the retail and consumer levels and reduce food losses along production and supply chains, including post-harvest losses" (United Nations Development Program, 2019). Food waste and its implications for water and energy resources need to be assessed. Data on food waste for both crops and livestock are needed at every point along the value chain, from the farm gate to the processing plant and to the consumer. These data are also needed to assess the potential for converting food waste into energy.

Future growth in supply and demand must be anticipated. Projections of future water availability are subject to uncertainties in climate model projections of precipitation amounts. Observations, tools, and models are needed to assess the uncertainties associated with water availability estimates. Uncertainties regarding the adoption rate of renewable energy technologies and electric cars complicate energy projections. Variable weather and fluctuating global food prices introduce year-to-year uncertainties into food scenarios. Near real-time data and information are needed to support rapid, localized responses on critical W-E-F Nexus issues. Artificial intelligence and neural network analysis tools hold the promise of optimizing resource availability and consumption and providing important guidance for decision-making.

Using indices to summarize the effects of multiple complex processes on a resource or human condition can be very useful 


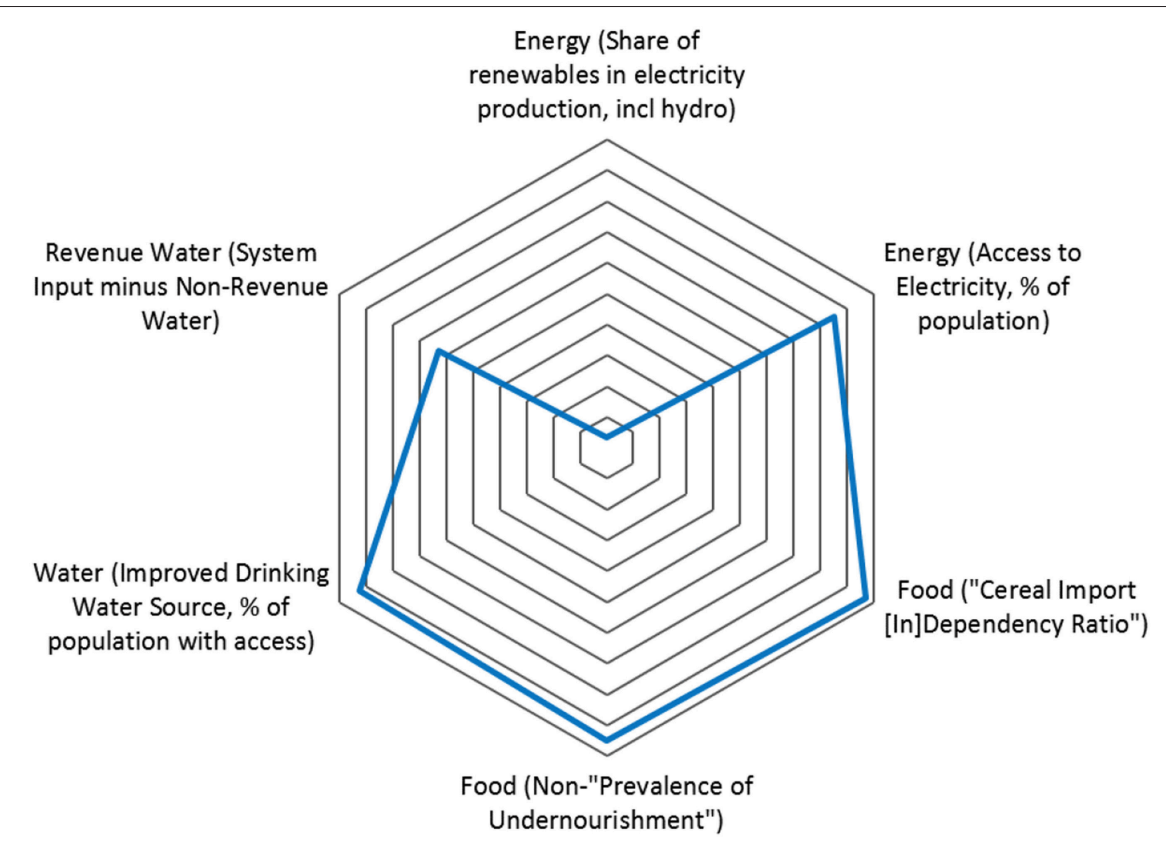

FIGURE 2 | Potential W-E-F Nexus indicator for application in South Africa (Simpson and Berchner, 2017).

for communicating with the public and policymakers (Smeets and Weterings, 1999). Indices could be designed for the W-E-F Nexus and used to measure progress toward its policy objectives. Figure 2 gives an example of a prototype W-E-F Nexus indicator from South Africa that monitors resource availability for water, energy, and food (Simpson and Berchner, 2017) that could be extended to other countries.

The risk concept can be used to rank sources of uncertainty and can help interpret longer-term scenarios and the likelihood and consequences of their realization. To address risk in a systematic way, all contributing factors (climate, consumer demand, and economics) and the interactions among them must be assessed. Risk frameworks can identify risk hotspots, requirements for trade-offs, and options for distributing risk. Evidence-based decisionmaking depends on reliable observation systems that provide data for a risk assessment framework. To make this approach feasible, however, W-E-F Nexus management must have access to all reliable data and information services whenever needed.

\section{DATA INPUTS}

The W-E-F Nexus data and information system (WEFDIS) proposed in this paper will make data and information products available to users. Data generally come from satellites and in situ data networks, but increasingly data from non-traditional data sources are also available. Communicating and consolidating data from different sources will rely on full access to data sources, standardized data formatting, and new data products that facilitate the design of solutions.
TABLE 2 | Preliminary assessment of variables essential to the W-E-F Nexus $\left({ }^{\star \star \star}\right.$ : very critical; ${ }^{\star \star}$ : critical, ${ }^{*}$ : helpful).

\begin{tabular}{|c|c|c|c|}
\hline Variable $\backslash$ sector & Water & Energy & Food \\
\hline Precipitation & 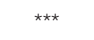 & $\star \star$ & 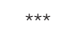 \\
\hline Air temperature & $\star *$ & 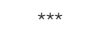 & *** \\
\hline Evapotranspiration/evaporation & $\star \star \star ~$ & ** & *** \\
\hline Water quality & 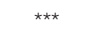 & ** & $\star \star *$ \\
\hline Water storage (reservoirs, lakes) & 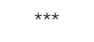 & 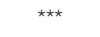 & * \\
\hline Soil moisture & 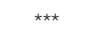 & * & *** \\
\hline Streamflow/runoff & $\star \star \star ~$ & $\star \star$ & * \\
\hline Groundwater & $* \star \star$ & * & ** \\
\hline Shortwave solar energy & * & 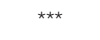 & $\star *$ \\
\hline Land use/land cover & ** & $\star \star$ & ** \\
\hline Primary productivity & * & ** & *** \\
\hline Boundary layer winds & * & 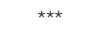 & * \\
\hline
\end{tabular}

Systems approaches should form the basis of new data collection and information systems. Arguably the development of and reliance on an information system is a core element of a W-E-F Nexus implementation and management strategy. Knowledge management and dissemination of best practices are critical for promoting the W-E-F Nexus and engaging stakeholders. Well-structured dialogue facilitated by a reliable data and information service and discussions stimulated by these services could contribute to policy development and action plans at national and international levels.

Synergies in planning a WEFDIS can be identified by assessing which sectors have similar data needs. Table 2 shows the results of a preliminary analysis of critical or essential variables and the 
TABLE 3 | Organizations and groups developing essential variables.

\begin{tabular}{ll}
\hline Organization/group & Data \\
\hline $\begin{array}{l}\text { Global Observing System for } \\
\text { Climate (GCOS) }\end{array}$ & Essential climate variables \\
$\begin{array}{l}\text { Group on Earth Observations } \\
\text { (GEO) }\end{array}$ & Essential variables for biodiversity and water \\
$\begin{array}{l}\text { Global Earth Observations } \\
\text { System of Systems }\end{array}$ & $\begin{array}{l}\text { The GEOSS water strategy: from } \\
\text { observations to decisions (Group on Earth } \\
\text { Observations, 2014) }\end{array}$ \\
GEO user needs studies & $\begin{array}{l}\text { Water (Friedl and Unninayar, 2010), energy, } \\
\text { and food }\end{array}$ \\
&
\end{tabular}

sectors that use them. It can be used as a tool for planning the WEFDIS data holdings and as a focus for discussions with users and stakeholders that will facilitate the articulation of priorities for the WEFDIS.

The approach to determining essential variables will be based on the efforts of a number of global organizations and groups (listed in Table 3). It also draws on the discussions held during the regional workshops in which participants gave their views on data needs. Unfortunately, not all sectors were equally represented at each workshop and the questions that elicited their responses were more directly addressed in some workshops than in others. Participants agreed on the importance of acquiring data and delivering data products at scales that capture the spatial variability and support informed decision-making.

\section{Satellite Data}

Workshop participants argued that any W-E-F Nexus information platform needs relatively complete data sets for the whole W-E-F Nexus system and offer the possibility to "drill down" to higher resolutions. Many key water and land cover variables can be measured or at least reliably estimated from space and standard products are routinely produced (precipitation, vegetation, shortwave radiation, evapotranspiration, soil moisture). Agriculture and energy are also supported in this way, although more data validation may be needed for some variables, such as crop type.

Satellites provide globally consistent data at regular intervals. Algorithms relate the radiances measured by satellites to physical atmospheric and surface variables such as precipitation and soil moisture. Table 4 lists current satellites from the National Aeronautics and Space Administration (NASA) and the European Space Agency (ESA) that provide global data sets for many of the essential W-E-F variables listed in Table 2. Satellite data can be used to supplement current in situ monitoring networks that may have inadequate data densities, continuity and consistency problems, diverse data formats, delayed reports, sensor failure, and political restrictions on free and open data exchange.

According to a recent survey of satellite needs and plans (National Academies of Sciences, Engineering, and Medicine, 2018), the W-E-F Nexus will soon benefit from the Surface Water Ocean Topography (surface water and river stage) mission and Landsat 9 (land use and cover) mission. Other new remote
TABLE 4 | Current NASA and ESA data sources for the W-E-F Nexus variables.

\begin{tabular}{|c|c|c|}
\hline Agency & Mission & Observation \\
\hline \multirow[t]{5}{*}{ NASA } & $\begin{array}{l}\text { Global Precipitation Measurement } \\
\text { (GPM) mission }\end{array}$ & Precipitation \\
\hline & $\begin{array}{l}\text { Moderate Resolution Imaging } \\
\text { Spectroradiometer (MODIS) mission }\end{array}$ & Vegetation cover and irrigation \\
\hline & $\begin{array}{l}\text { Soil Moisture Active Passive (SMAP) } \\
\text { mission }\end{array}$ & Soil moisture \\
\hline & Landsat 8 & Land use and cover \\
\hline & $\begin{array}{l}\text { Gravity Recovery and Climate } \\
\text { Experiment (GRACE) Follow-On } \\
\text { Mission }\end{array}$ & Groundwater and soil moisture \\
\hline \multirow[t]{4}{*}{ ESA } & Sentinel-1 & Floods, water bodies, and wetlands \\
\hline & Sentinel-2 & $\begin{array}{l}\text { Urban, forest, and agricultural } \\
\text { environments }\end{array}$ \\
\hline & Sentinel-3 & $\begin{array}{l}\text { land monitoring, vegetation, land } \\
\text { surface temperatures, altimetry, } \\
\text { and lake water quality }\end{array}$ \\
\hline & $\begin{array}{l}\text { Soil Moisture and Ocean Salinity } \\
\text { (SMOS) mission }\end{array}$ & Soil moisture, freeze/thaw \\
\hline
\end{tabular}

sensing platforms include drones and cube satellites, which promise to increase the frequency of satellite maps of land surface conditions (National Academies of Sciences, Engineering, and Medicine, 2018). Space agencies in Japan, China, India, France, Germany, and Brazil also make satellite data available for WE-F Nexus monitoring. NASA and ESA have specific niches for the W-E-F Nexus issues embedded in research activities such as ESA's joint program with Future Earth and NASA's Food Security program.

The National Oceanic and Atmospheric Administration and the European Organization for the Exploitation of Meteorological Satellites collect regional data from geostationary satellites. Their satellites provide data from the same domain every $30 \mathrm{~min}$ or less over their field of coverage overcoming the low repeat times associated with observations from polarorbiting satellites.

\section{Limitations}

In some cases, imperfect algorithms are used to convert measured signals into values for a particular variable (e.g., root zone soil moisture), resulting in increased uncertainty for these measurements. Depending on resolution and sensor technology, polar-orbiting satellites may have repeat times of $24 \mathrm{~h}$ to 15 days, limiting their usefulness for monitoring rapidly developing phenomena. Maintaining continuity in Earth observation data used for analysis and assessment purposes is also critical for monitoring the W-E-F Nexus. Some nations find it difficult to use satellite data because they cannot handle high data volumes, nor can they acquire specialized analysis and mapping software and associated expertise due to resource limitations.

\section{In situ Data Capabilities}

Precise local, high-frequency observations provide more accurate data for many variables at the point of application. For example, 
measurements of streamflow, soil moisture, and groundwater at a specific location are best determined by in situ measurements at that location. In many cases, in situ data can provide historical context because data sets are often multi-decadal. They are also important for satellite data calibration.

Citizen science data could become a new source of in situ WE-F Nexus data. It encompasses mobile phone photos, narrative information, and tweets that can be submitted by students and laypersons. In some cases, citizen science data archiving has taken the form of mobile apps that collect water quality data from multiple devices and assemble it into a single database. The data producers, scholars, and citizens who provide data are currently responsible for their quality control.

\section{Limitations}

Operational networks that provide W-E-F Nexus observations need attention. Governments support these networks for public health and safety and economic reasons, while the private sector often supports local observations for operational efficiency and added value. However, coverage by hydrometric stations for the W-E-F Nexus and, by association, the SDGs is affected by the decline in streamflow gauges that has taken place in many countries (Fekete et al., 2015). Nations frequently maintain multipurpose networks, which may have complications for addressing specific W-E-F Nexus issues. For example, if precipitation data are collected only at airports, they may not provide the best inputs for streamflow prediction in nearby basins during the convective rain season.

In situ measurements of water quality need to be enhanced to strengthen environmental monitoring. Governments need to ensure industries provide accurate information on their emissions to the environment and account for missing information. Furthermore, more effort is needed to harmonize global and local data sets for water quality. Integrating observations for the W-E-F Nexus provides an opportunity to integrate emerging Nexus capabilities and concepts with traditional data programs. However, the range of possible data and analysis capabilities is so diverse that it must be prioritized through consultation with stakeholders and users using the list in Table 2 as a starting point.

\section{Socio-Economic Data Capabilities}

Social, economic, and biophysical data are needed to support W-E-F Nexus decisions. Information systems need to support the development and implementation of effective, integrated policies for the W-E-F Nexus and account for their impact on future outcomes. Information systems need to inform decision-makers of development opportunities (e.g., agricultural incentives for economic and environmental sustainability) and regulatory requirements. Socio-economic data include economic data, census data, trade statistics, employment profiles for each sector, studies of demographics and social behavior, and general and targeted surveys. Food and energy data are collected by many governments for trade strategies and reporting purposes. Given the space and time scales involved and the diversity of socio-economic information, it is challenging to incorporate them into a data and information platform focused on highresolution physical data. New tools are required to make full use of narrative-oriented and qualitative citizen data and to develop procedures and standards for quality controlling these data. New directions for the acquisition of data are emerging through "big data" projects such as the UN's Planet Pulse project.

\section{Limitations}

Existing economic databases generally provide high-level, lowresolution data, allowing only macro-level explanations of the W-E-F Nexus. National economic data need to be downscaled to state and county levels for further analysis. Data on property ownership and use and associated legal rights are needed by nations to support W-E-F Nexus governance research, but they are not collected systematically across all nations. For some countries and some issues, census statistics and citizen science may prove to be the best tools for tracking policy implementation, particularly where regular and systematic data collection programs exist. Site-specific data are needed to validate census and national reporting data.

The development and application of new analysis techniques that produce reformatted and gridded socio-economic data that can be better integrated with physical data. For example, mapped data on regulations and ordinances have been used to successfully coordinate policy implementation in areas with multiple agencies and overlapping responsibilities. A geographical approach also enables the integration of biophysical and socio-economic data in addressing these governance problems (see Taniguchi et al., 2017 for an example). A similar W-E-F Nexus service could identify hotspots and provide updates on the impacts of storms, floods, and droughts as well as longer-term W-E-F Nexus information that only needs annual updates. Targeted monitoring is also important to assess the impacts and benefits of W-E-F Nexus management and interventions.

\section{Data Provenance and Coordination}

As a principle, data systems should be designed to maximize the value of information for the users. Reduced data latency is needed because the value of data for W-E-F Nexus decisions tends to decrease with time. Given the many scales of W-E-F Nexus decisions, it would be helpful to have regional data frameworks to facilitate the transfer of data and improve its utility for national, regional, and local scales. An international framework (with reporting requirements) for the W-E-F Nexus and strengthened links with the SDG framework could advance this aspect of W-E-F Nexus implementation.

It is important to have realistic data expectations. Without data, planners will not be aware of changes in resources and the environment. Without links to policy, benefits to the Nexus could become somewhat transient and overridden by legislation and directives from other government levels at other times. Arguably, the most efficient way to support users is to develop a platform through which data, information, tools, models, and policy updates are made fully interactive, accessible, and useable. 


\section{MODELS AND DATA ASSIMILATION}

Models integrating different data sets are needed to support decision-making. Models can also be useful to W-E-F Nexus implementation: they consolidate available knowledge and assess interactions among processes and sectors. Integrated data products resulting from model and data assimilation system outputs can be combined to fill data gaps, reduce uncertainty, and improve spatial scale. Models can also be used to upscale and downscale data and results to provide outputs that meet the needs of decision-makers for information at different scales.

Some data needs are known but the desired spatial resolution and temporal frequency can only be achieved with assimilation systems or models. Many data types are difficult to downscale to counties and towns; however, Earth observations and data assimilation models can help provide local estimates and disaggregate to local scales using algorithms. Trade-offs may be needed between spatial and temporal scales. Well-focused, mission-oriented questions and assessments can be used to help define scale, accuracy, and data latency requirements, along with other W-E-F Nexus data needs.

Models used in W-E-F Nexus information systems should include biophysical, socio-economic, agent, policy, ecological, and landscape models. Optimally, they will function in the same environment, draw data from the same databases, and use common definitions and units. Predictive models also play a key role in making projections that can underpin planning decisions. Predictive and scenario models should assess and project the consequences of long-term changes such as climate change and consequences of different development trajectories. A suite of models could be combined in different ways to assess future opportunities. For example, to examine food security, researchers should combine climate or weather, crop, and food demand models. The development of this model suite should engage experts from each sector and focus on an architecture that can provide an interactive hierarchy of interlinked models. Improving the accuracy of extended-range weather and climate forecasts for essential W-E-F variables (at 30-90 days) should also be a priority research issue to support shorter-term projections of W-E-F Nexus conditions.

Data assimilation models are needed to fill data gaps and generate the best data products possible for the scales at which decisions are being made. Integrated data analysis systems should also combine different data types, upscale data for comparison purposes, and downscale system outputs to support decisions and problem identification at local scales. Solutions include merging data sets or using a model to unite different data types and to estimate missing data. It is important to develop assimilation capabilities that can combine in situ and satellite data to produce integrated products. NASA's Land Data Assimilation System and Land Information System are examples of systems that meet these requirements.

\section{IMPLEMENTING THE W-E-F NEXUS DATA AND INFORMATION SYSTEM (WEFDIS)}

\section{Scope of the WEFDIS}

A "one-stop" system designed to meet the data and information needs of W-E-F Nexus managers and document the interactions of the constituent sectors could strengthen the W-E-F Nexus approach. As managers from each sector gain confidence in the system and in each other, they could be encouraged to identify and discuss policy inconsistencies and issues, thus building a foundation for more in-depth W-E-F Nexus planning and decision-making. Integrated information systems should provide planners and decision-makers with Nexus data as well as access to all the data from each sector. In particular, a WEFDIS would ingest in situ data and space-based information and produce integrated products related to essential W-E-F Nexus variables and critical processes.

Addressing specific data requests through an integrated data and information system can pose some structural challenges. Open, standardized metadata catalogs could help in crossreferencing data sets from different sectors. Metadata should be complete, including information on data latency, scales, and measurement methodologies. Water, energy, and food metadata should be collected in a systematic fashion, using a series of templates (questions, data, models, and scenario options). However, since not all the data that are incorporated into the information system will have been originally collected with the purpose of addressing W-E-F Nexus issues, the original purpose of the data collection effort should be included in the metadata. Synergies should be used when collecting and curating data at one center. Data stored in existing portals also need to be evaluated and incorporated or linked wherever feasible. Blockchain technologies offer ways of ensuring the reliability of data and metadata even though they come from many different sources and are accessed for many purposes.

Cloud computing services are increasingly being used in support of data services to provide rapid access to large quantities of data. This approach removes the need for downloading individual data files because the analysis can be undertaken directly at the source. Data dissemination and use is facilitated by format protocols used in the cloud, which in turn encourages data merging and comparison. Cloud computing should be implemented where it is practical and affordable to do so. The computer systems supporting cloud storage also provide powerful capabilities for running W-E-F Nexus models and data assimilation systems.

In order to communicate with most policymakers at the national level, a W-E-F Nexus indicator test bed needs to be developed and applied within the WEFDIS. For developing countries, where national data sets are often far less uniform, the WEFDIS should build on other networks and systems in their region. For example, NASA and the U.S. Agency for International Development have developed a network of regional information systems known as SERVIR to support data availability in developing countries. The SERVIR network currently consists of five regional hubs providing large satellite data sets and 
products. Other transmission systems such as GEONETCast have become popular for transmitting data between agencies without the Internet. These systems could be used to transmit products from the WEFDIS.

\section{Developing and Implementing a WEFDIS Network}

Critical steps in developing a W-E-F Nexus data and information system are described below. Some actions will be sequential, while many can be carried out in parallel.

1. Undertake user surveys and conduct consultative workshops to identify or confirm W-E-F Nexus data needs and strategies to support decision-making at regional and local scales. This consultative process should clarify data needs for multiscale, transdisciplinary research as well as the basic data and services. Users would be given opportunities to specify their priorities among the available variables, including those listed in Table 2, for a given country or region and to clarify their needs for data resolution, frequency, and latency.

2. Provide scientific support for an integrated WEFDIS. The data, information, and tools needed for decision support at multiple scales should be assessed. Consultations would be held with groups experienced in managing large data portals, such as GEO, the World Climate Research Programme, the World Data Centers, and institutions that manage large data systems in the private sector, before finalizing the design for WEFDIS.

3. Assess existing information platforms to determine which features could contribute to a WEFDIS. In addition to evaluating the most desirable system features, mutually beneficial links should be developed to support the W-EF Nexus community. A number of relevant information portals, such as the Climate and Environmental Data Retrieval system, which makes its data and comprehensive information available to users (Toussaint et al., 2007), can be used as examples of best practices in creating a WEFDIS. Appendix 1 provides a preliminary listing of other information platforms that should be considered in this assessment. Services requiring consolidation across the water, energy, and food sectors should be identified so that shared platforms with national and international data components can be developed.

4. Develop an inventory of the existing tools, models, and databases that should be included in the WEFDIS and the desirable links with other data portals. This would include assembling the appropriate data sets from each sector that meet data standards and are needed for W-E-F Nexus decision-making.

5. Co-design information system outputs that meet the needs of decision-makers and can help build trust between data providers and users. In an ideal participatory process, scientists, experts, and stakeholders identify critical W-E-F Nexus issues and action plans are collaboratively developed. This participatory model, which has been used successfully in W-E-F Nexus studies in Japan (Endo, 2015), could be implemented more broadly by incorporating a WEFDIS into W-E-F Nexus planning.
6. Conduct pilot projects that test a basic data and information system and its interactions with users. To ensure systems are user-friendly for these pilot studies, global data sets would be subdivided into smaller data sets covering geographical areas of interest for the pilot project and stored as an additional set of products within the system. Information could be displayed through Web-based applications, information dashboards, and time series viewers (Few, 2013). The output formats would be adjusted to cover the range of user preferences and required services.

7. Develop a governance structure to support effective implementation and promote system sustainability and to provide a set of operating principles for the system management group to follow. The WEFDIS will be highly dependent on the availability of regular data inputs routinely harvested from open databases. In many countries (but not all), publicly funded research and data collections are freely and openly accessed. One essential principle that should not be compromised is a commitment to free and open data access at all steps in the process. Participation in a regional WEFDIS by a nation should mean its agencies are fully committed to providing data to the system under an open data policy. Data collection costs are high and it is often not economically efficient to acquire them for just one application. In countries where data are not freely available, governments should be encouraged to support the provision of data to the WEFDIS at no cost.

8. Where appropriate, institutional models should be considered to see how best to combine the efforts of a few national and regional centers into a global network. GCOS, which successfully advanced climate data by developing clear statements about the role of data and data services within the UN Framework Convention on Climate Change, would be a good model for the W-E-F Nexus especially if similar levels of policy support could be developed.

A number of data-related considerations and data flows for the WEFDIS are shown in Figure 3. The system would ingest numerical and textual data in a number of formats and languages. Automated data transfer will be used wherever possible to retrieve data, although specialized data may only be available by exploring the Web. The system design elements will be developed through consultations with representatives of each sector. The internal language used for communicating data (NetCDF, HDF, or another language) and the expected products and services will be part of the design. A metadata library would be maintained to allow users to determine which data are available. Information about data quality and completeness would be supplied by data providers and provided through a metadata library. Integrated modeling systems would be used to assess the internal consistency of these data for W-E-F Nexus decisionmaking and to facilitate projections of future conditions.

\section{Developing User Capacity}

As with other data systems, the benefits of WEFDIS will go to those who have the capacity to use it. The user criteria of near real-time information, free access to data, knowledge of 


\section{Data Flows in the W-E-F Data and Information Platform}

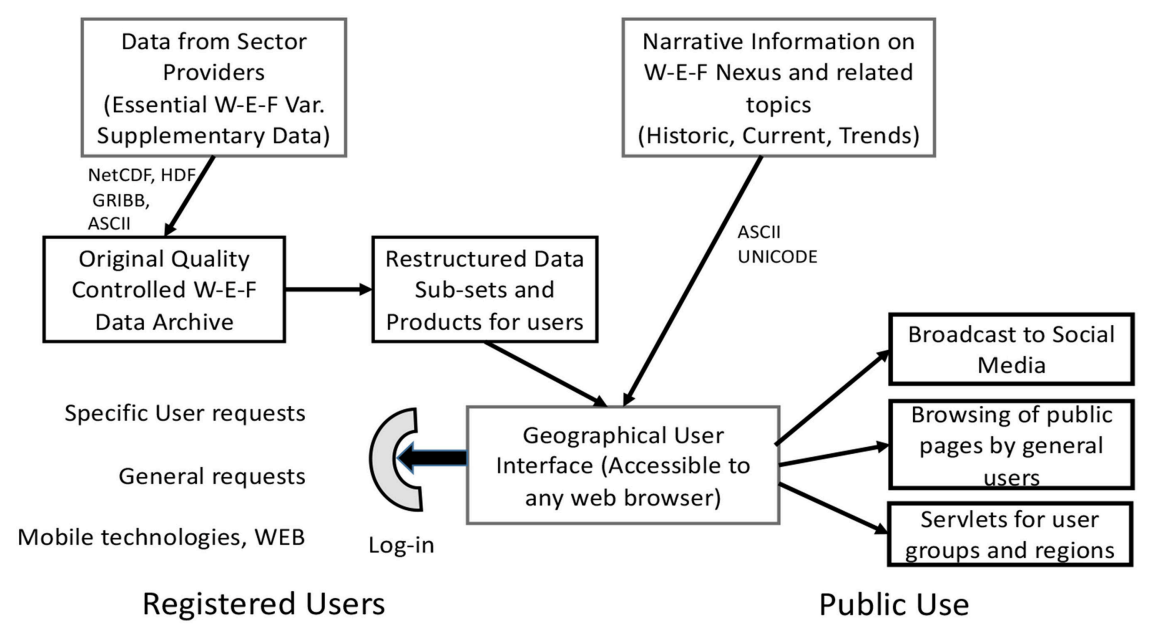

FIGURE 3 | A proposed structure for the W-E-F Nexus data and information system.

how to use the data, and translating the information effectively into every nation's official languages may not always be fully possible. Countries and organizations worldwide should be given an opportunity to gain these capabilities. To this end, a cadre of experts who can use these data and train others to do likewise should be developed. Providing all nations with equal access to the system in their own official languages will be a challenge but the system should be capable of serving major language groups.

Evolving user capability needs to be considered. Given that farmers and other data users are making extensive use of mobile phones, it will be important for the WEFDIS to effectively interface with mobile networks and technologies. The potential to uptake information and data from these distributed sources should be developed and local data sets should be integrated into larger domain products. This engagement of the local public could contribute to better and more widely accepted W-E-F Nexus products.

Regional W-E-F Nexus discussions and coordination should be promoted for joint ownership of information resources and assets. Data collection activities and system maintenance and experts that curate the service should all be continuously funded.

Capacity development must occur at both the infrastructure and the individual levels. To develop parity among users, the discrepancy in Internet accessibility and speed among developing and developed countries should be addressed. This "digital divide" prevents users in the developing world from accessing and using many data products that could contribute to managing the W-E-F Nexus. Training experts to interpret data for decisionmakers is a central capacity development need, especially in developing countries.

\section{CONCLUSIONS}

This paper described the opportunities for bringing data from the latest observational systems together within a new multidisciplinary data and information platform design to support the implementation of an integrated W-E-F Nexus planning and decision-making management approach. The paper reviewed the information that is required by Nexus decision-makers, described the available satellite, in situ, and socio-economic data, and introduced the role of models and assimilation systems to fill the data gaps. The paper focused on the design of a data and information system and outlined eight steps needed to develop and implement such a system. While the plan is ambitious, it is more focused than most of the other W-E-F Nexus implementation approaches that were discussed during the W-E-F Nexus regional workshops. Furthermore, this system is not only a stand-alone system, it can also be used in conjunction with other more policy-oriented implementation approaches if the appropriate data and model needs are satisfied.

The paper identified a number of key W-E-F Nexus issues that have not received adequate attention, including food waste and its implications for resource use efficiency; the source, use, and fate of water used for fracking; and the estimation of water use and water quality at local, national, and global scales. The paper also explored the implications of these issues for the $\mathrm{W}$ E-F Nexus, and for monitoring W-E-F Nexus variables. These gaps would be most comprehensively addressed within a W-E-F Nexus framework.

The paper concluded by outlining elements that should be integrated in a W-E-F Nexus data and information platform. Although most of the technologies mentioned are not new, their integration into a multi-sectoral application that supports resource management and stewardship of related environmental sectors is novel. The paper mapped out a pathway for bringing information from different sectors into a single system to meet the needs of an emerging W-E-F Nexus management perspective. It outlined a way to engage users in the system's design and, through pilot projects, to ensure they will have the training and experience necessary to exploit the system. System development would go hand in hand with W-E-F Nexus implementation. The hypothesis that access to data and information would promote acceptance of the changes and adjustments that would come with the adoption of the W-E-F Nexus approach seems sound 
based on the rationale presented but remains to be proven by a successful pilot project. Next steps in the implementation process should involve the development of implementation teams for pilot projects at different scales with support from national governments and international agencies. In addition, engagement by the UN and other international agencies would be needed to ensure that the international dimensions of the $\mathrm{W}$ E-F Nexus are effectively addressed and that policies essential to maintaining the free exchange of $\mathrm{W}$-E-F Nexus data among and within countries are followed.

\section{AUTHOR CONTRIBUTIONS}

The author confirms being the sole contributor of this work and has approved it for publication.

\section{ACKNOWLEDGMENTS}

The author gratefully acknowledges the Belmont Forum, Future Earth, and the Sustainable Water Future Programme for

\section{REFERENCES}

Endo, A. (2015). An Integrated Map to Coordinate Coastal Policies and Water Resource Policies in Japan: Visualizing a Water, Energy, and Food Nexus. Retrieved from http://cwrr.ukzn.ac.za/docs/default-source/wef_workshop/ tamus-future-earth-dc-wef-workshop.pdf?sfvrsn=4 (accessed March 12, 2019).

Fekete, B. M., Robarts, R. D., Kumagai, M., Nachtnebel, H.-P., Odada, E., and Zhulidov, A. V. (2015). Time for in situ renaissance. Science 349, 685-686. doi: $10.1126 /$ science.aac7358

Few, S. (2013). Information Dashboard Design: Displaying Data for At-a-Glance Monitoring, 2nd Edn. Burlingame, CA: Analytics Press.

Food and Agriculture Organization (2017). The Future of Food and Agriculture: Trends and Challenges. Retrieved from http://www.fao.org/3/a-i6583e.pdf

Friedl, L., and Unninayar, S. (2010). GEO Task US-09-01a: Critical Earth Observations Priorities. Retrieved from https://sbageotask.larc.nasa.gov/ Water_US0901a-FINAL.pdf

Group on Earth Observations (2014). The GEOSS Water Strategy: From Observations to Decisions, ed R. Lawford. Tokyo: Japanese Aerospace Exploration Agency.

Haupt, S. E., Kosovi,ć, B., Jensen, T., Lazo, J. K., Lee, J. A., Jiménez, P. A., et al. (2018). Building the Sun4Cast system: improvements in solar power forecasting. BAMS 99, 121-135. doi: 10.1175/BAMS-D16-0221.1

Liu, J., Yang, H., Cudennec, C., Gain, A. K., Hoff, H., Lawford, R., et al. (2017). Challenges in operationalizing the water-energyfood nexus. Hydrol. Sci. J. 62, 1714-1720. doi: 10.1080/02626667. 2017.1353695

National Academies of Sciences, Engineering, and Medicine (2018). Thriving on Our Changing Planet: A Decadal Strategy for Earth Observation From Space (Washington, DC: The National Academies Press). doi: 10.17226/ 24938

Ringler, C., Bhaduri, A., and Lawford, R. (2013). The nexus across water, energy, land and food (WELF): potential for improved resource use efficiency? COSUST 5, 617-624. doi: 10.1016/j.cosust.2013.11.002 supporting the four regional W-E-F Nexus workshop through a Belmont Forum (National Science Foundation) grant that led to many of the insights presented in this paper. The contributions of approximately 200 workshop participants from five continents are also acknowledged. In addition, the author thanks Dr. Claudia Pahl-Wostl, the project's co-Principal Investigator, who organized the governance discussions for each workshop, and Dr. Anik Bhaduri, Executive Director of the Water-Futures Progamme, who administered the Belmont Forum funding. The contributions of the four workshop's local organizers are grateful acknowledged: Dr. Rabi Mohtar (Texas A\&M, USA), Dr. Kim Watson (Karlsruhe, Germany), Dr. Aiko Endo (Research Institute for Humanity and Nature, Japan) and Dr. Sylvester Mpandeli, (Water Research Commission, South Africa), and Drs. Sabine Stuart-Hill and Graham Jewitt (University of KwaZuluNatal, South Africa). The author also thanks the NASA Water Applications Program, and its director, Dr. Bradley Doorn, for support through the GESTAR program at Morgan State University, and Andrée-Anne Boisvert, Peter Lawford, and Dr. Sushel Unninayar for their editorial comments.

Simpson, G., and Berchner, M. (2017). Measuring integration - towards a water-energy-food nexus index. Water Wheel 16, 22-23. Available online at: https://journals.co.za/docserver/fulltext/waterb_v16_n1_ a5.pdf? expires $=1555447879 \& \mathrm{id}=\mathrm{id} \&$ accname $=$ guest $\&$ checksum $=$ 4EF66DB7D985B44AAC9FB66D50045467

Smeets, E., and Weterings, R. (1999). Environmental Indicators: Typology and Overview. Retrieved from https://www.eea.europa.eu/publications/TEC25 (accessed March 12, 2019).

Taniguchi, M., Endo, A., Gurdak, J. J., and Swarzenski, P. (2017). Waterenergy-food nexus in the Asia-Pacific region. J. Hydrol. 11, 1-8. doi: 10.1016/j.ejrh.2017.06.004

Tett, G. (2015). The Silo Effect: The Peril of Expertise and the Promise of Breaking Down Barriers. New York, NY: Simon and Shuster.

Toussaint, F., Lautenschlager, M., and Luthardt, H. (2007). World data center for climate data - support for the CEOP project in terms of model output. $J$. Meteorol. Soc. Jpn. 85A, 475-485. doi: 10.2151/jmsj.85A.475

United Nations Development Program (2019). Goal 12: Responsible Consumption and Production. Retrieved from http://www.undp.org/content/undp/en/ home/sustainable-development-goals/goal-12-responsible-consumptionand-production.html\#targets (accessed March 12, 2019).

Vörösmarty, C. J. (2017). A possible approach to the E2E WEF Stressor study. Paper Presented at the Water Assessment and WEF Information System Workshop (College Park, MD: University of Maryland).

World Economic Forum (2014). Global Risks 2014. Retrieved from http://reports. weforum.org/global-risks-2014/ (accessed March 12, 2019).

Conflict of Interest Statement: The author declares that the research was conducted in the absence of any commercial or financial relationships that could be construed as a potential conflict of interest.

Copyright (c) 2019 Lawford. This is an open-access article distributed under the terms of the Creative Commons Attribution License (CC BY). The use, distribution or reproduction in other forums is permitted, provided the original author(s) and the copyright owner(s) are credited and that the original publication in this journal is cited, in accordance with accepted academic practice. No use, distribution or reproduction is permitted which does not comply with these terms. 


\section{APPENDIX 1}

Brief description of some information platforms and portals that address the needs of one or more of the W-E-F Nexus sectors

Various information systems that support some aspect of the W-E-F Nexus should be examined to assess their needs for data handling, modeling, and information dissemination capabilities. Systems to be assessed include GEO's Global Agricultural Monitoring Initiative (www.geoglam.org) for monitoring crop conditions, the Global Drought Information System (www. drought.gov/gdm/current-conditions) for monitoring drought, the GEO Global Water Sustainability Initiative website (under construction), and the World Data Centre for Climate. Other platforms that support water management include ESA's Thematic Exploitation Platforms (https://tep.eo.esa.int) and the Copernicus projects (www.copernicus.eu/projects/ connectingeo).

W-E-F Nexus-related information projects include the Vision on Technology for a Better World, a system that facilitates data processing and distribution and analyzes global trends affecting the W-E-F Nexus (https://vito.be/en), and the GIZ Water, Energy \& Food Security Resource Platform (http://www.water-energyfood.org/). An example for the energy sector is a system being developed by Haupt et al. (2018) to forecast solar energy outputs. The water sector is covered by the Aqueduct system, developed by the Water Resources Institute, which has more than a decade of experience in shaping outputs for those needing water risk assessment tools (http://aqueduct.wri.org).

Each of these platforms could be assessed separately so that their most useful elements can be incorporated into the WEFDIS. 